\title{
THE QUEER VARIATIONS IN THE HUMAN LIVER AND RECENT INSIGHTS INTO THEIR CLINICAL IMPORTANCE
}

\section{Geeta Anasuya. D *1, T. Jones Eben Raj ${ }^{2}$, Sheela Grace Jeevamani ${ }^{3}$.}

${ }^{{ }^{*} 1}$ Assistant Professor, Department of Anatomy, KMCH Institute of Health Sciences and Research, Coimbatore, India

2 Tutor, Department of Anatomy, ACS Medical college and Hospital, Velapanchavadi, Chennai, India

${ }^{3}$ Professor \& Head, Department of Anatomy, Karpagam Faculty of Medical Sciences and Research, Coimbatore, India.

\section{ABSTRACT}

Background: Liver is the largest of the abdominal viscera occupying a substantial portion of abdominal cavity. Even though anatomical variations are rare, their knowledge is important for clinicians and radiologists. The present study was performed to evaluate the morphology of liver and its variations.

Methodology: This observational study was conducted on 50 formalin fixed adult livers obtained from Department of anatomy, KFMSR, Coimbatore, Tamilnadu during the year 2016 and 2017 . Different morphological variations like variations in size of right and left lobes, accessory lobes and fissures, pons hepatis segmentis were observed and their photographs were taken.

Results: Out of 50 livers, accessory fissures were seen in 20 (40\%) specimens, accessory liver lobes in 12 specimens $(24 \%)$, lingular process of right lobe in $7(14 \%)$ specimens, lingular process of left lobe in 7 (14\%) specimens, pons hepatis segmentis in $9(18 \%)$ specimens.

Conclusion: Majority of variations were seen regarding accessory fissures on posterior and inferior surfaces. A thorough knowledge of these findings will be useful for physicians and they also provide enough information to avoid confusion for clinicians during surgical and radiological procedures.

Key words: Variations of liver, Right lobe, Left lobe, Accessory fissures, Accessory lobes, Riedel's lobe.

Corresponding Author: Dr Geeta Anasuya. D, MD, Assistant Professor, Department of Anatomy, KMCH Institute of Health Sciences \& Research, Coimbatore- 641014 , Tamil Nadu, India.

E-Mail: geetagee1@gmail.com

Access this Article online

Quick Response code

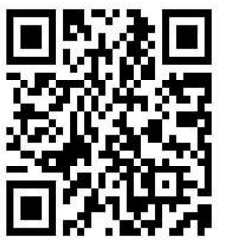

DOI: $10.16965 /$ ijar.2020.200

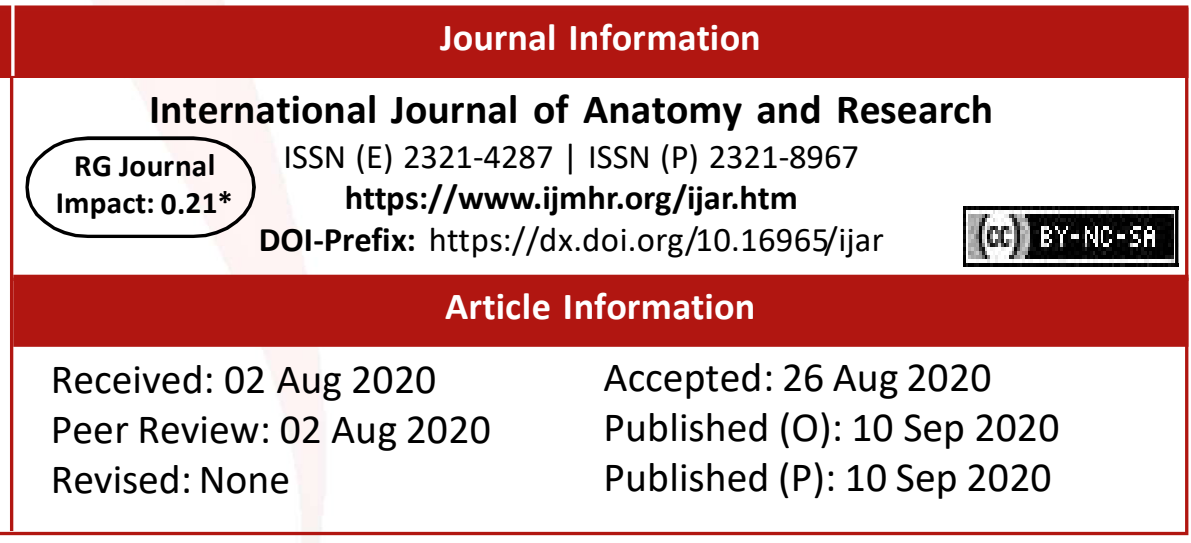

\section{INTRODUCTION}

The liver is wedge shaped organ situated under the right dome of the diaphragm and mainly occupies the right hypochondrium and epigastric region. It is divided into anatomical right and left lobes by the attachment of falciform ligament, fissure for ligamentum venosum and fissure for ligamentum teres.
Functionally, an imaginary plane Cantlie's line which joins the fossa of gall bladder to the Inferior vena cava divides the liver into right and left lobes.

The caudate and quadrate lobes are part of right lobe of liver. The gall bladder fossa is situated on the inferior surface of right lobe and fundus of gall bladder is situated beyond the inferior 
border of liver [1] (Fig.1) The gross variations of human liver have been classified as congenital and acquired [2]. The congenital anomalies of liver can be divided into anomalies due to defective development and anomalies due to excessive development. Defective development of left lobe of liver leads to gastric volvulus, whereas defective development of right lobe may remain latent or progress to portal hypertension $[3,4]$. The excessive development of liver results in the formation of accessory lobes of liver which may carry the risk of torsion. Acquired variations in liver could be due to the pressure given by diaphragm, peritoneal ligaments and other organs in relation with liver so developed during lifetime of a person [5].

Acquired changes in the liver gross features include the tongue like processes of both lobes, small left lobe, deep renal impression with "corset" type constriction etc. [4].

Netter classified the morphological variations of liver into 6 types as described in Table-1[6]. The knowledge of anatomy of liver is required for good surgical outcome, diagnostic imaging and minimally invasive surgical procedures.

\section{MATERIALS AND METHODS}

The present study was undertaken on 50 formalin fixed human livers obtained from the department of anatomy, KFMSR, Coimbatore, Tamilnadu. During routine dissection for undergraduate medical students, liver specimens were removed from the human cadavers and preserved in $10 \%$ formalin. These preserved livers were carefully studied for the presence of accessory lobes, accessory fissures and abnormalities in various lobes of liver. The lobes of the liver, right lobe, left lobe, caudate lobe and quadrate lobe were studied. The findings observed were noted appropriately and the specimens were photographed.

Inclusion criteria: Livers with no obvious gross deformities were studied.

Exclusion criteria: Specimens showing features of cirrhosis, damaged livers, those livers with gross changes in size and shape were excluded from the study.

\section{OBSERVATIONS AND RESULTS}

Out of 50 livers studied in the department of anatomy, KFMSR, accessory lobes were found in 12 specimens (24\%) [Fig.8a ]. Accessory fissures on posterior and inferior surface were found in 20 specimens (40 \%) [Fig.2]. Enlarged right lobes were seen in 19 specimens (38\%) [Fig.5], enlarged left lobes were seen in 5 specimens ( $10 \%$ ) [Fig.10 ]. Pons hepatis segmentis was found in 13 specimens (26\%) [Fig.6], liver with lingual process of right lobe were seen in 7 specimens (14\%) [Fig.7], lingual process of left lobe were seen in 7 specimens (14\%) [Fig.12]. Other variations were also noted like deep renal impression with corset type constriction in 4 specimens (8\%) [ Fig. 8c], diaphragmatic or costal grooves in 14 specimens (28\%) [ Fig.4,11a]. Riedel's lobe in 1 specimen (2\%) [Fig.9], hypoplastic left lobe were observed in 3 specimens (6\%) [Fig.11b].

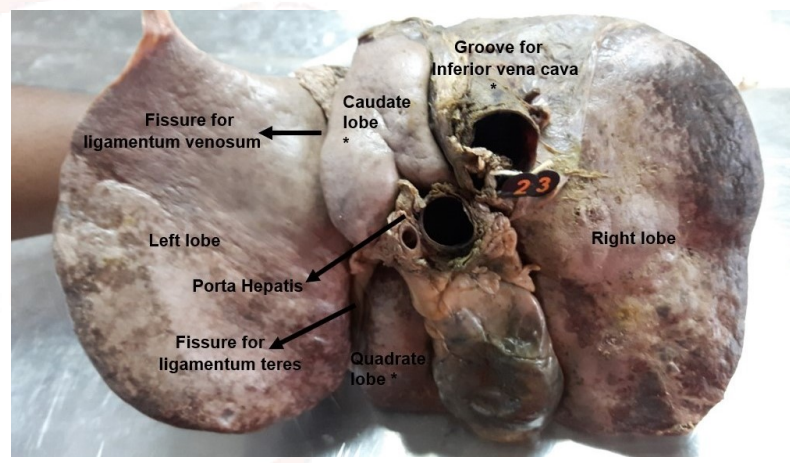

Fig. 1: Showing the visceral surface of normal liver.

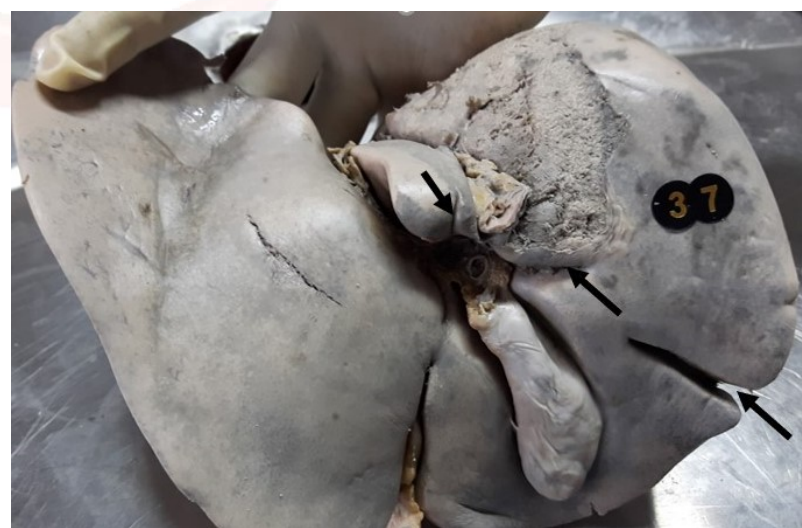

Fig. 2: Black arrows showing accessory fissures.

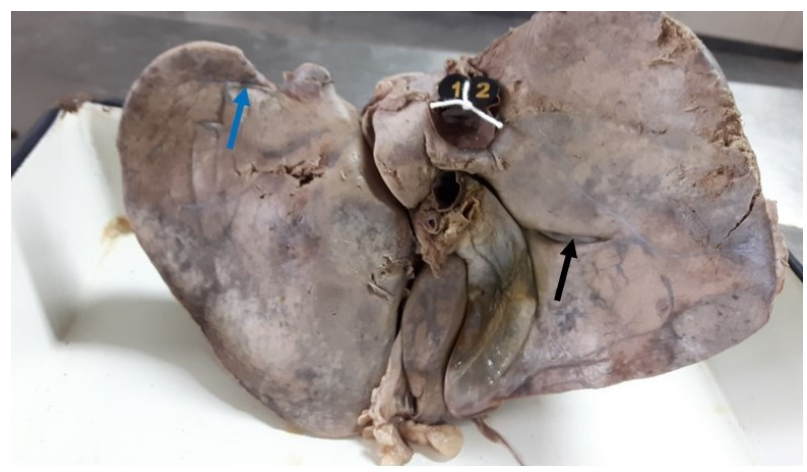

Fig. 3: Black arrow showing Rouviere's sulcus, blue arrow showing superficial vein. 


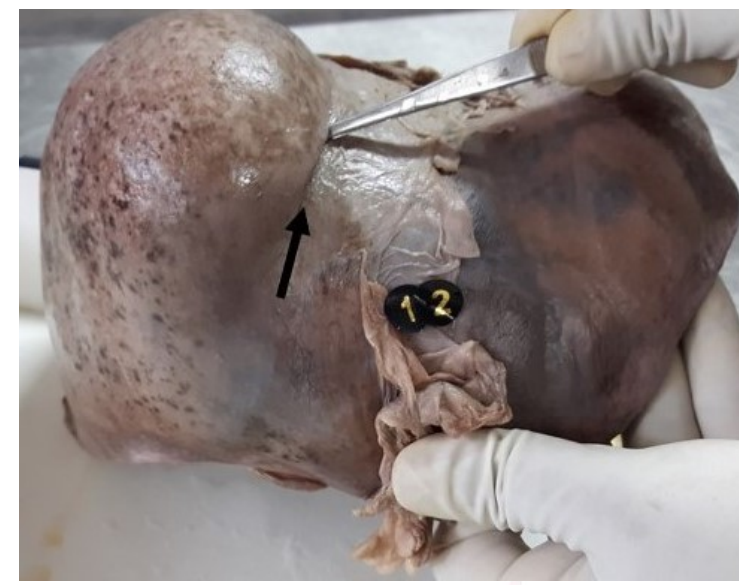

Fig. 4: Deep costal impression with very small left lobe Netter's type 1.

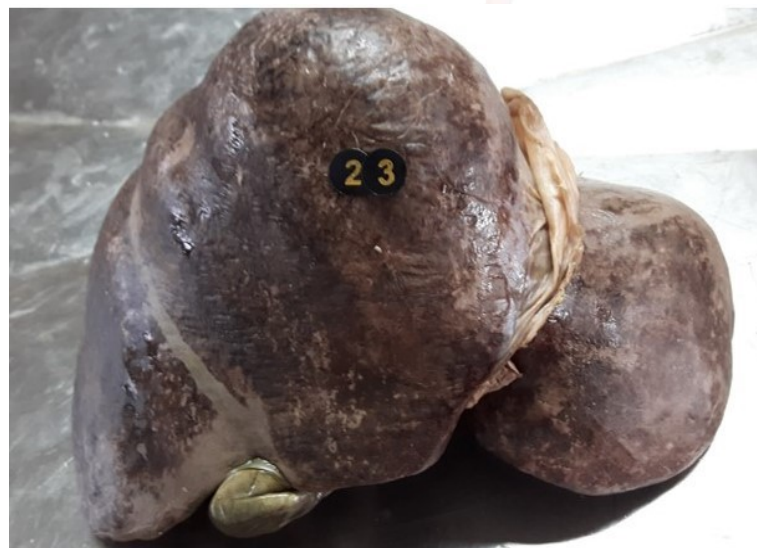

Fig. 5: Conical shape of liver with very small left lobe Netter's type 2.

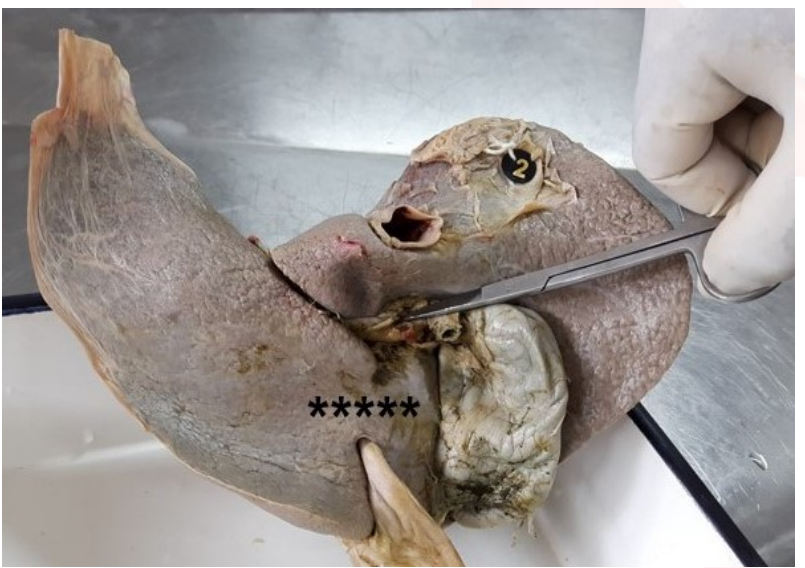

Fig. 6: Liver showing pons hepatis Netter's type 3.

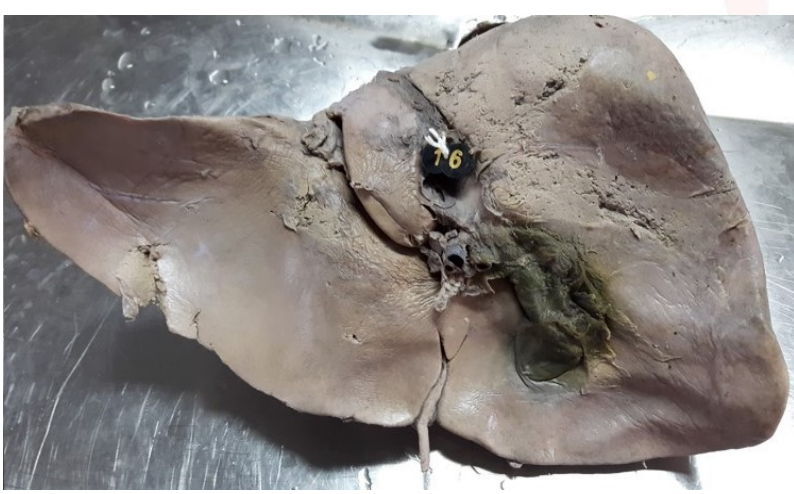

Fig. 7: Shows tongue like process on right lobe Netter's type 4.

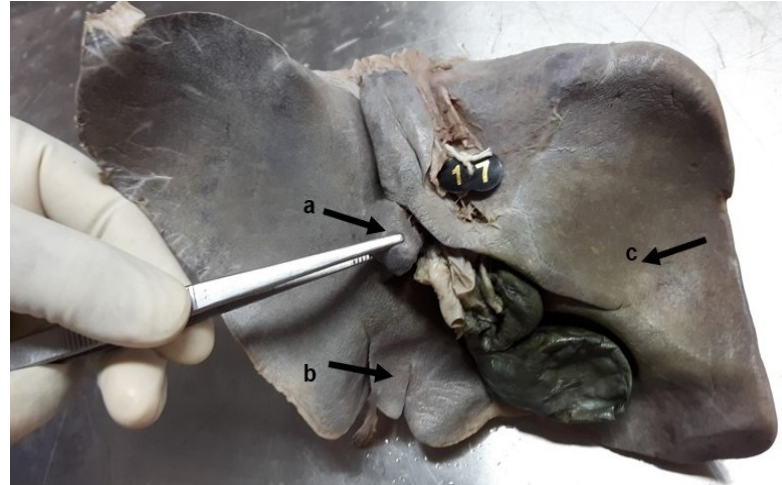

Fig. 8: (a) Shows accessory lobe near caudate lobe, (b) tongue like projection in quadrate lobe (c) deep renal impression and corset type of constriction Netter's type 5.

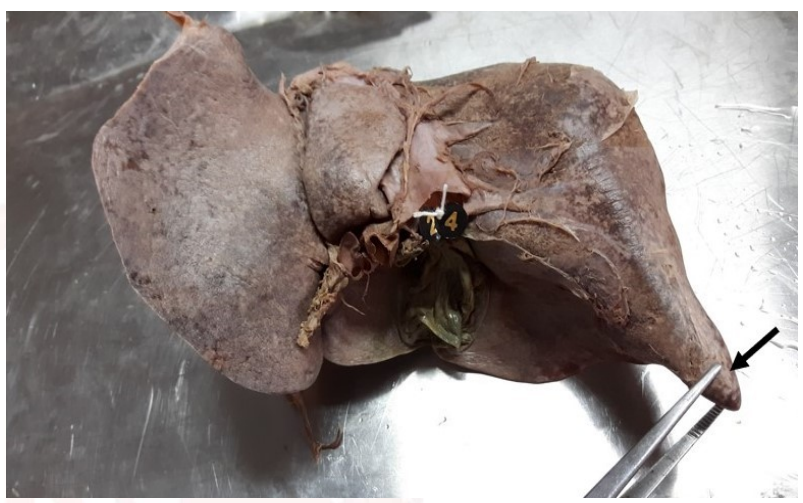

Fig. 9: Black arrow showing Riedel's lobe.

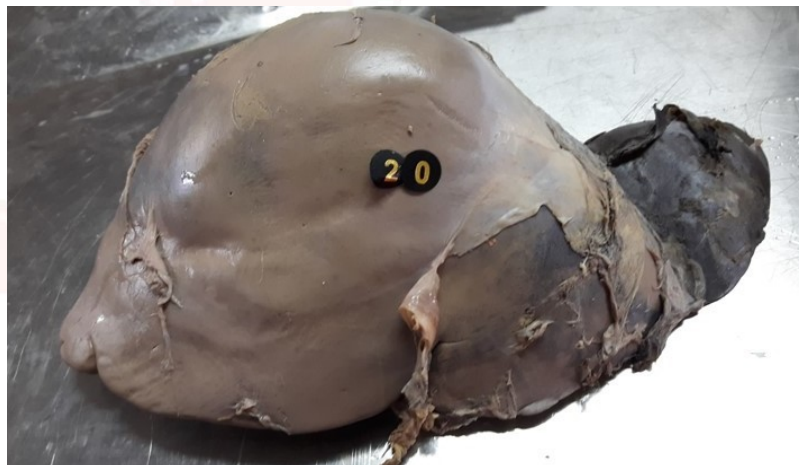

Fig. 10: Showing saddle like liver with elongated left lobe of liver or Beaver's lobe.

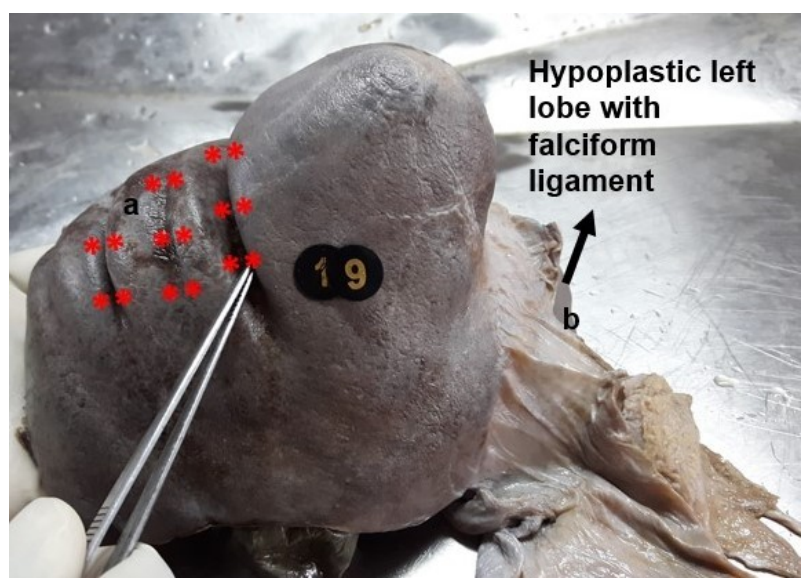

Fig. 11: (a) Dotted stars showing multiple deep diaphragmatic grooves on the right superior surface of liver Netter's type 6 (b) Arrow showing Hypoplastic left lobe. 


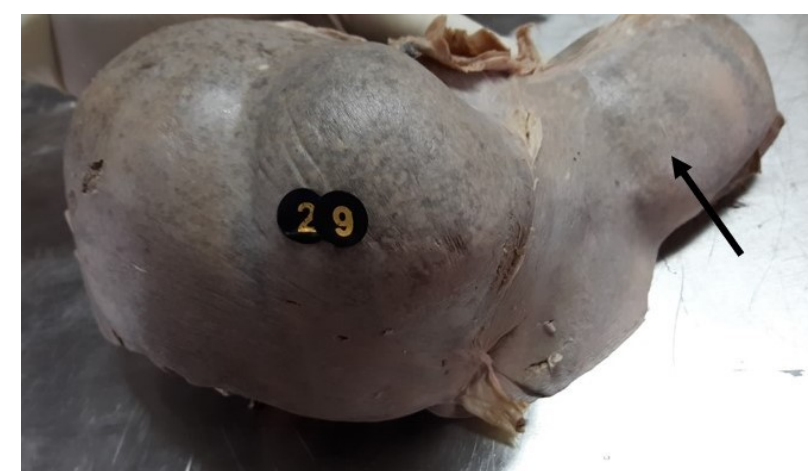

Fig. 12: Black arrow showing lingular process of left lobe.

Table 1: Showing Netter's classification of morphological types of liver.

\begin{tabular}{ccl}
\hline S.no & Types & \multicolumn{1}{c}{ Features } \\
\hline $\mathbf{1}$ & Type 1 & Very small left lobe, deep costal impressions \\
\hline $\mathbf{2}$ & Type $\mathbf{2}$ & Very small or complete atrophy of left lobe \\
\hline $\mathbf{3}$ & Type $\mathbf{3}$ & $\begin{array}{l}\text { Transverse saddle like liver relatively large left } \\
\text { lobe }\end{array}$ \\
\hline $\mathbf{4}$ & Type $\mathbf{4}$ & Tongue like process Right lobe \\
\hline $\mathbf{5}$ & Type $\mathbf{5}$ & $\begin{array}{l}\text { Very deep renal impressions with corset type } \\
\text { constriction }\end{array}$ \\
\hline $\mathbf{6}$ & Type $\mathbf{6}$ & Diaphragmatic grooves \\
\hline & & \\
\hline
\end{tabular}

\section{DISCUSSION}

Table 2: Showing the number and percentage of morphological variations of liver.

\begin{tabular}{clcc}
\hline S.no & \multicolumn{1}{c}{ Findings } & Number & Percentage \\
\hline $\mathbf{1}$ & Accessory liver lobes & 12 & $\mathbf{2 4}$ \\
\hline $\mathbf{2}$ & $\begin{array}{l}\text { Accessory fissures on posterior and } \\
\text { inferior surface of liver }\end{array}$ & 20 & $\mathbf{4 0}$ \\
\hline $\mathbf{3}$ & Enlarged right lobe & 19 & $\mathbf{3 8}$ \\
\hline $\mathbf{4}$ & Enlarged left lobe & 5 & $\mathbf{1 0}$ \\
\hline $\mathbf{5}$ & Pons hepatis segmentis & 13 & $\mathbf{2 6}$ \\
\hline $\mathbf{6}$ & Liver with diaphragmatic grooves & 14 & $\mathbf{2 8}$ \\
\hline $\mathbf{7}$ & Liver with deep renal impressions and & 4 & $\mathbf{8}$ \\
\hline $\mathbf{8}$ & corset type of constriction & $\mathbf{2}$ & $\mathbf{1 4}$ \\
\hline $\mathbf{9}$ & Liver with lingual process of right lobe & 7 & $\mathbf{1 4}$ \\
\hline $\mathbf{1 0}$ & Riedel's lobe & $\mathbf{7}$ & $\mathbf{2}$ \\
\hline $\mathbf{1 1}$ & Hypoplastic left lobe & $\mathbf{1}$ & $\mathbf{6}$ \\
\hline $\mathbf{1 2}$ & Atrophy of left lobe & 3 & - \\
\hline $\mathbf{1 3}$ & Absent quadrate lobe & Nil & - \\
\hline & & Nil & \\
\hline
\end{tabular}

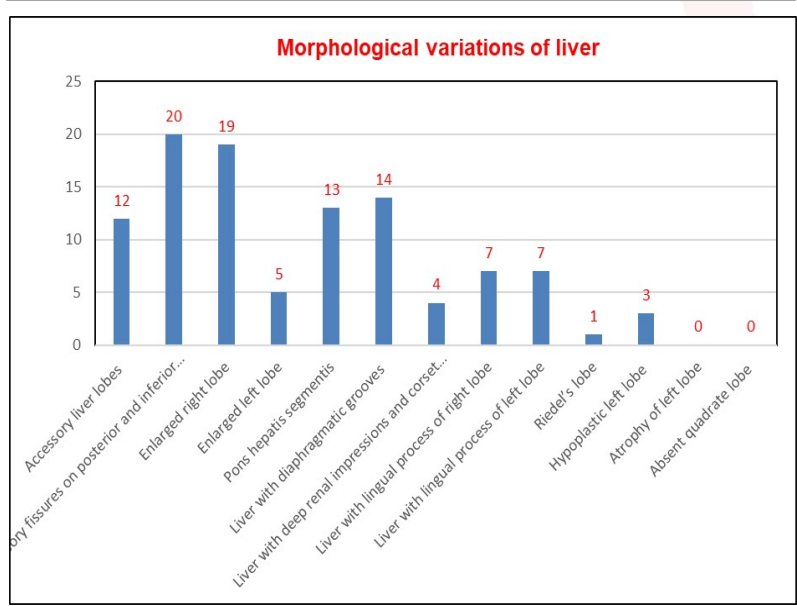

Chart 1: Detailed analysis showing morphological variations of liver (number basis).
In the present study morphological variations like accessory lobes, accessory fissures on posterior, inferior and superior surfaces, enlarged right lobe, pons hepatis segmentis, lingual process of right and left lobes, deep renal impression with corset type constriction, diaphragmatic or costal grooves, Reidel's lobe were observed. The number and the percentage of the variations have been presented in the Table -2 and chart 1 respectively.

Table 3: Showing number and percentage of Netter's morphological types of liver.

\begin{tabular}{cccc}
\hline S.No & Findings & Number & Percentage \\
\hline $\mathbf{1}$ & Netter's type 1 liver & 18 & 36 \\
\hline $\mathbf{2}$ & Netter's type 2 liver & 4 & 8 \\
\hline $\mathbf{3}$ & Netter's type 3 liver & 6 & 12 \\
\hline $\mathbf{4}$ & Netter's type 4 liver & 7 & 14 \\
\hline $\mathbf{5}$ & Netter's type 5 liver & 5 & 10 \\
\hline $\mathbf{6}$ & Netter's type 6 liver & 14 & 28 \\
\hline
\end{tabular}

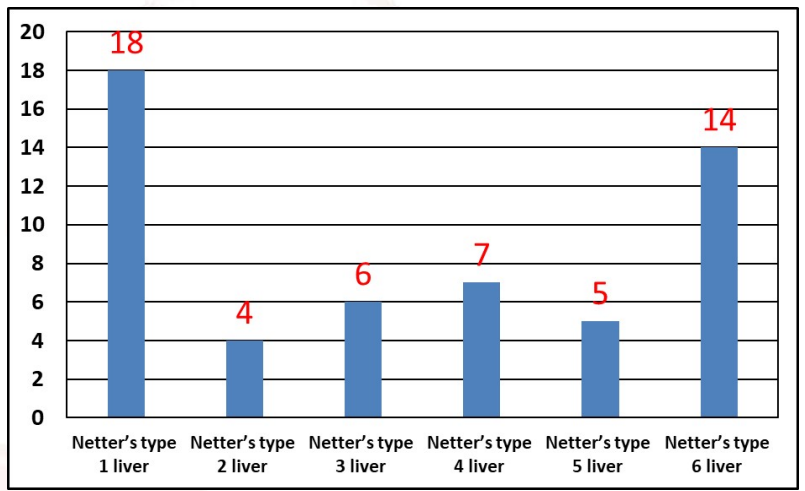

Chart 2: Showing number and percentage of Netter's morphological types of liver (number basis).

Morphological variations of the liver are common like abnormal fissures, abnormal lobes, pons hepatis segmentis, deep diaphragmatic grooves [7]. In the present study accessory fissures were noted in different areas of liver like near to porta hepatis, near to base of gall bladder, along the inferior border [Fig. 2]. Accessory fissures were also observed in caudate lobe, in quadrate lobe, superior surface. Quadrate lobe is continuous with left lobe due to the presence of an incomplete fissure for ligamentum teres.

It has been mentioned that the Rouviere's sulcus is the inferior accessory hepatic fissure that extends from the right of hilum anterior to the caudate process. It contains the right branch of the portal vein. It is also an essential landmark during laparoscopic cholecystectomy and also to identify biliary pedicle to the resection 
of segments $\mathrm{V}$ and $\mathrm{VI}[9]$. They may represent the deep course of hepatic veins superficially. If it is because of course of hepatic veins, it may be useful to the hepatic biliary surgeons [10]. It is a reliable landmark during severe acute inflammation of liver.

The Rouviere's sulcus identification is an additional hoax that could be used to avoid bile duct injuries [21] because cystic duct and the cystic artery lie anterosuperior to the sulcus and the common bile duct lies below the level of it [22]. By operating ventral to the sulcus, the surgeon could confirm that they are working safe. So, Rouviere's sulcus could be regarded as the surgeon's anatomical array. Livers showing Rouviere's sulci have been observed in the present study [Fig.3].

Accessory fissures are the important springs for diagnosis of faults during imaging. It may be mistaken for liver cyst, hematoma or abscess when there is collection of fluid in these fissures. Metastatic tumor cells getting lodged into these spaces may mimic intrahepatic focal lesions [8]. They are the areas of weaker zones with a reduced amount of vascularity and could be useful during resection $[11,12]$. They play an important role during segmental resection of liver and laparoscopic techniques. According to Champetier J. et al, hepatic anomalies can be divided into two categories, anomalies due to defective development and anomalies due to excessive development of the liver [13-23].

Morphological variations of the liver are irregularities in the form, occurrence of one or more accessory lobes or presence of cyst, less common abnormalities are atrophy or complete absence of one of the lobes [15].

A less common abnormality is occurrence of one or more accessory liver lobes [13]. In the present study, accessory lobes were observed near caudate and quadrate lobes [Fig. 8a \& b]. It has been found out in Indian population, that accessory lobes are present in $10 \%$ of the population [14] and might be erroneous for a lymph node due to its small size and removed during the surgeries.

Accessory lobes may occur in abundant places. Infra-hepatic position is mostly common. They may also trigger tumor. Riedel's lobe is the best known example of a sessile accessory lobe [15]. It is a downward tongue like projection of the anterior edge of the right lobe of the liver to the right of gall bladder [16]. Riedel's lobe was detected in 1 specimen in the extant study [Fig.9]. The anatomical familiarity of the Reidel's lobe is very important as sometimes malignant tumors could arise from the lowest part of Riedel lobe $[11,13]$.

Apart from the congenital variations, acquired changes which include lingular process of left lobe were observed in 7 specimens (14\%) [Fig. 12] , Netter's type 4, tongue like process of right lobe [Fig.7], hypoplastic left lobe Netter's type 2, [Fig 11b],deep renal impression with corset type of constriction, Netter's type 5 livers were also observed [Fig 8c]. The number and percentage of Netter's morphological types of liver have been represented in Table 3 and chart 2 respectively.

While segmental anatomy of liver research attains the extreme consideration, there are also studies that focus on common or rare morphological variants. With increasing dependency on radiological imaging for disease diagnosis and laparoscopic procedures, acquaintance of common anatomical surface variations of the liver is perilous for the best patient inferences [24]. Moreover, while most hepatic variants are dormant, there have been documented cases of clinical manifestations caused by variant morphology [18].

Other gross variations like pons hepatis connecting the left lobe with the quadrate lobe have been reported [13]. Pons hepatis segmentis were observed in 13 specimens (26\%) in our study [Fig.6]. Saritha et al [19] have reported it in $4 \%$ of livers, while Joshi et al [20] have found higher incidence of $30 \%$ of pons hepatis. In cases of pons hepatis bridging the fissure for ligamentum teres, the fissure would not be visualized properly and the extents of right and the left lobes may be mistaken [20]. In the present study, diaphragmatic impressions were also observed in 14 specimens (28\%) [Fig.11a], that is Netter's type 6 liver.

\section{CONCLUSION}

The asymptomatic patients with accessory lobes do not need resection. Surgery should be performed 
in individuals with serious complications. The familiarity of the liver variations is very essential for anatomists, for the surgeons to plan appropriate surgical approaches and also to radiologists for circumventing diagnostic errors during imaging by plain radiographs, ultrasound or computerized tomography. The appreciation of Rouviere's sulcus forms a reliable landmark during severe acute inflammation and should be a valued reckon for the surgeon's anatomical acquaintance.

\section{Conflicts of Interests: None}

\section{REFERENCES}

[1]. Strandring.S.Gray's Anatomy: The Anatomical Basis of Clinical Practice 40th edition. NewYork: Churchill Livingstone 2008;3441-46.

[2]. A.C. Nagato, M.A.S. Silva, E.T.L.Trajano et al., Quantitative and morphological analyses of different types of human liver. Journal of Morphological Sciences, 2011;28(4):275-279.

[3]. G. B. Daver, G. D. Bakshi, A.Patil, S.Ellur, M.Jain, and N.G. Daver. Bifid liver in a patient with diaphragmatic hernia. Indian Journal of Gastroenterology 2005;24(1):27-28.

[4]. M.F.Royer, Vias Biliares e Pancreas, Guanabara Koogan, Rio de Janeiro, Brazil, 1959.

[5]. V.V. Phad, S.A. Syed, R.A. Joshi. Morphological variations of liver Int. J. Health Sci. Res., 2014;4:119-124.

[6]. Netter FH. Atlas of Human Anatomy .2ed. New york:18 Guilford Press, 2000.

[7]. Chaudhari HJ, Ravat MK, Vaniya VH, Bhedi AN. Morphological study of Human Liver and its Surgical importance. J Clin Diagn Res.2017 Jun;11(6):AC09AC12.

https://doi.org/10.7860/JCDR/2017/24467.10020 PMid:28764141 PMCid:PMC5535334

[8]. Y. H. Auh, W.A. Rubenstein, and K. Zirinsky. Accessory fissures of the liver: CT and sonographic appearance. American Journal of Roentgenology 1984;143(3):565-572.

https://doi.org/10.2214/ajr.143.3.565

PMid:6331736

[9]. S.O. Cawich, M.T. Gardner, R. Shetty, N.W. Pearce, V. NaraynsinghAccessory inferior sulci of the liver in an afro-caribbean population Int. J. Biomed. Sci., 2016;12:58-64.

[10]. F.B. Othman, A.A. Latiff, F.H. Suhaimi, S. Das Accessory sulci of the liver. An anatomical study with clinical implications Saudi Med. J., 2008;29:12471249.

[11]. Macchi V., Feltrin G., Parenti A. Diaphragmatic sulci and portal fissures. J. Anat., 2003;202:303-308. https://doi.org/10.1046/j.1469-7580.2003.00160.x PMid:12713270 PMCid:PMC1571083

[12]. Macchi V., Porzionato A., Parenti A. et al. Main accessory sulcus of the liver. Clin. Anat., 2005;18(1):39- 45. https://doi.org/10.1002/ca.20030

PMid:15597371

[13]. C.G.Fraser. Accessory lobes of the liver. Annals of Surgery 1952;135(1):127-129. https://doi.org/ 10.1097/00000658-195201000-00020 PMid:14895157 PMCid:PMC1802276

[14]. Patil S, Sethi M, Kakar S. Morphological study of human liver and its surgical importance. Int J Anat Res.2014; 2(2):310-4.

[15]. Muktyaz H, Nema U, Suniti MiR, Mahboobul H. Anatomical study of Accessory Sulci of Liver and its Clinical Significance in North Indian Population. Int J Med Health Sci.2013;2(2):224-9.

[16]. Reitermeier RJ, Butt HR, Baggenstones AH. Riedel's lobe of the liver. Gastroenterology. 1958;34:109095.

https://doi.org/10.1016/S0016-5085(58)80082-7

[17]. Soo MS, Adatepe MH. Metastatic lesions arising in a Riedel's lobe. Findings from a sulfur colloid liverspleen scan. Clin Nucl Med 1990;15:814-815. https://doi.org/10.1097/00003072-19901100000010 PMid:1963389

[18]. Vinnakota S, Jayasree N. A new insight into the morphology of the human liver: a cadaveric study. International Scholarly Research Notices. 2013;2013.

https://doi.org/10.5402/2013/689564

PMid:25938101 PMCid:PMC4392949

[19]. Saritha S, Ramani, Nagajyothi, et al. Cadaveric study of morphological variations in the human liver and its clinical importance. International Journal of Medical Science And Clinical Inventions 2015;2(6):1020-31.

[20]. Joshi SD, Joshi SS, Athavale SA. Some interesting observations on the surface features of the liver and their clinical implications, Singapore Med J 2009;50: 715-719.

[21]. Honda, Goro, et al. The critical view of safety in laparoscopic cholecystectomy is optimized by exposing the inner layer of the subserosal layer. Journal of Hepato-Biliary-Pancreatic Sciences, 2009;16(4):445-49.

https://doi.org/10.1007/s00534-009-0060-3 PMid:19259610

[22]. Zubair, Muhammad, et al. Rouviere's sulcus: A guide to safe dissection and laparoscopic cholecystectomy. Pakistan Journal of Surgery, 2009;22(2):11921.

[23]. Champetier J, Yver R, Letoublon C, Vigneau B. A general review of anomalies of hepatic morphology and their clinical implications. Anatomia Clinica, 1985;7(4):285-299.

https://doi.org/10.1007/BF01784645 PMid:3833290

[24]. Rumack CM, Wilson S, Charboneau WJ, Levine D. The liver. In: Wilson S, Withers C, editors. Diagnostic Ultrasound. 4th.Vol.1.Philadelphia, PA: ElsevierMosby; 2011. pp.78-84. 